Article

\title{
Atmospheric Pressure Plasma Polymerized Oxazoline-Based Thin Films-Antibacterial Properties and Cytocompatibility Performance
}

\author{
Pavel St'ahel ${ }^{1}{ }^{\circledR}$, Věra Mazánková ${ }^{2,3}$, Klára Tomečková ${ }^{2}$, Petra Matoušková ${ }^{4}$, \\ Antonín Brablec ${ }^{1}$, Lubomír Prokeš ${ }^{1}$, Jana Jurmanová ${ }^{1}$, Vilma Buršíková ${ }^{1} \mathbb{1}$, Roman Přibyl ${ }^{1}$, \\ Marián Lehocký ${ }^{5}$, Petr Humpolíček ${ }^{5}$, Kadir Ozaltin ${ }^{5}$ and David Trunec ${ }^{1, *}$ \\ 1 Department of Physical Electronics, Faculty of Science, Masaryk University, Kotlářská 2, \\ 61137 Brno, Czech Republic; pstahel@physics.muni.cz (P.S.); abr92@sci.muni.cz (A.B.); \\ luboprok@gmail.com (L.P.); janar@physics.muni.cz (J.J.); vilmab@physics.muni.cz (V.B.); \\ 451677@mail.muni.cz (R.P.) \\ 2 Faculty of Chemistry, Institute of Physical and Applied Chemistry, Brno University of Technology, \\ Purkyňova 118, 61200 Brno, Czech Republic; mazankova@fch.vut.cz (V.M.); \\ ktomeckova11@gmail.com (K.T.) \\ 3 Department of Mathematics and Physics, Faculty of Military Technology, University of Defence in Brno, \\ Kounicova 65, 66210 Brno, Czech Republic \\ 4 Faculty of Chemistry, Institute of Food Science and Biotechnology, Brno University of Technology, \\ Purkyňova 118, 61200 Brno, Czech Republic; matouskova@fch.vut.cz \\ 5 Centre of Polymer Systems, Tomas Bata University in Zlín, Trida Tomase Bati 5678, \\ 76001 Zlín, Czech Republic; lehocky@post.cz (M.L.); humpolicek@utb.cz (P.H.); \\ kadirozaltin@hotmail.com (K.O.) \\ * Correspondence: trunec@physics.muni.cz; Tel.: +420-549-497-763
}

Received: 1 November 2019; Accepted: 6 December 2019; Published: 12 December 2019

\begin{abstract}
Polyoxazolines are a new promising class of polymers for biomedical applications. Antibiofouling polyoxazoline coatings can suppress bacterial colonization of medical devices, which can cause infections to patients. However, the creation of oxazoline-based films using conventional methods is difficult. This study presents a new way to produce plasma polymerized oxazoline-based films with antibiofouling properties and good biocompatibility. The films were created via plasma deposition from 2-methyl-2-oxazoline vapors in nitrogen atmospheric pressure dielectric barrier discharge. Diverse film properties were achieved by increasing the substrate temperature at the deposition. The physical and chemical properties of plasma polymerized polyoxazoline films were studied by SEM, EDX, FTIR, AFM, depth-sensing indentation technique, and surface energy measurement. After tuning of the deposition parameters, films with a capacity to resist bacterial biofilm formation were achieved. Deposited films also promote cell viability.
\end{abstract}

Keywords: antibiofouling; plasma polymer; oxazoline

\section{Introduction}

Polyoxazolines (POx) are a promising and important class of polymers that have attracted substantial attention recently due to their antibiofouling properties [1,2] and good biocompatibility [3]. Usually, POx are prepared by living-cationic ring-opening polymerization, which is a lengthy wet process conducted in organic solvents. POx thin films are created in a subsequent step, which needs to be tailored for any particular type of substrates $[4,5]$. Other possible polymerization techniques are photocoupling [6] and grafting [7], both of which require the premodification of substrates. 
So, the formation of polyoxazoline coatings using conventional methods is a slow and complex multistep procedure, which can be conducted only on a limited range of substrates. The difficulties of these conventional methods can be overcome via plasma polymerization. Plasma polymerization is known to be a suitable method for the deposition of many biomaterial coatings [8,9]. Plasma polymerization is in the class of plasma-enhanced chemical vapor deposition (PECVD) methods, which are successfully used for example for thin film deposition [10], surface modification [11,12], or growing of nanomaterials [13-15]. Plasma deposition of 2-methyl-2-oxazoline and 2-ethyl-2-oxazoline has already been performed in low-pressure radio frequency (RF) discharge [16-18]. However, the necessity to use expensive vacuum pumping systems is the disadvantage of low-pressure plasma deposition techniques. Recently, plasma deposition in atmospheric pressure discharges has become a new promising technology due to its economic and ecological advantages. A suitable discharge type for plasma deposition at atmospheric pressure is a homogeneous dielectric barrier discharge (DBD), which can be obtained in nitrogen. This discharge type is called atmospheric pressure Townsend-like discharge (APTD) [19]. APTD in the mixture $\mathrm{N}_{2}-\mathrm{SiH}_{4}-\mathrm{N}_{2} \mathrm{O}$ was used for $\mathrm{SiO}_{2}$ thin film deposition [20], APTD in the mixture of $\mathrm{N}_{2}$ with hexamethyldisiloxane (HMDSO) was used for deposition of organosilicon polymer films [21]. The properties of films deposited in APTD are different from properties of films deposited in low-pressure discharges due to different plasma and discharge parameters, e.g., ion energies in APTD are lower than those in low pressure discharges. The film properties can be changed by increasing the substrate temperature at deposition [22]. Recently, POx coatings were deposited using discharges at atmospheric pressure. Atmospheric pressure helium plasma jet was used for plasma polymerization of 2-methyl-2-oxazoline on heated silicon substrates [23]. The film stability in buffer solution was substantially improved when the films were deposited at substrate temperatures above $50{ }^{\circ} \mathrm{C}$ in these experiments. Near atmospheric pressure (0.5 bar) plasma polymerization of 2-alkyl-2-oxazolines in argon DBD was used for the study of the influence of the aliphatic side-chain length on the plasma polymerization process conditions as well as on the properties of the deposited coatings [24].

In the current study, POx thin films were deposited in nitrogen APTD using 2-methyl-2-oxazoline as monomer. The substrate temperature was changed from $20^{\circ} \mathrm{C}$ to $150{ }^{\circ} \mathrm{C}$ at the film deposition. This temperature change leads to different film properties. The films with the highest biocompatibility and the best antibiofoulding properties were obtained at the deposition with a substrate temperature of $150{ }^{\circ} \mathrm{C}$.

\section{Materials and Methods}

\subsection{Materials}

Glass plates (soda-lime glass, $150 \times 100 \mathrm{~mm}$, thickness $1.1 \mathrm{~mm}$ ) were used as substrates for deposition. 2-Methyl-2-oxazoline (98\%, Sigma-Aldrich, Munich, Germany) was used as a monomer for plasma deposition. Preliminary antibacterial tests were done with Staphyloccocus epidermidis (CCM 4418), supplied by the Czech Collection of Microorganisms in Brno. Bacterial culture was grown into commercial BHI medium (Brain Heart Infusion Broth, HiMedia, Mumbai, India). Basic Red 2 (Safranin $\mathrm{O}$, Sigma-Aldrich, Munich, Germany) stain was used for biofilms visualization. Other antibacterial tests were done with Staphylococcus aureus (CCM 4516) and Escherichia coli (CCM 4517), both supplied by the Czech Collection of Microorganisms in Brno.

\subsection{Plasma Deposition}

Plasma polymerization was performed in a custom-built reactor (metallic chamber with dimensions $500 \mathrm{~mm} \times 500 \mathrm{~mm} \times 500 \mathrm{~mm}$ ) with dielectric barrier discharge [22]. The discharge was generated between two planar metal electrodes. The bottom electrode with dimensions $150 \mathrm{~mm} \times 55 \mathrm{~mm}$ could be heated using a heating spiral, and the electrode temperature was measured with a thermocouple. The upper electrode with dimensions $55 \mathrm{~mm} \times 40 \mathrm{~mm}$ was covered with glass, 
$1.5 \mathrm{~mm}$ in thickness. A slit $2 \mathrm{~mm}$ wide in the center of the upper electrode was used for the supply of working gas with the monomer to the discharge. The electrode system is shown in Figure 1.

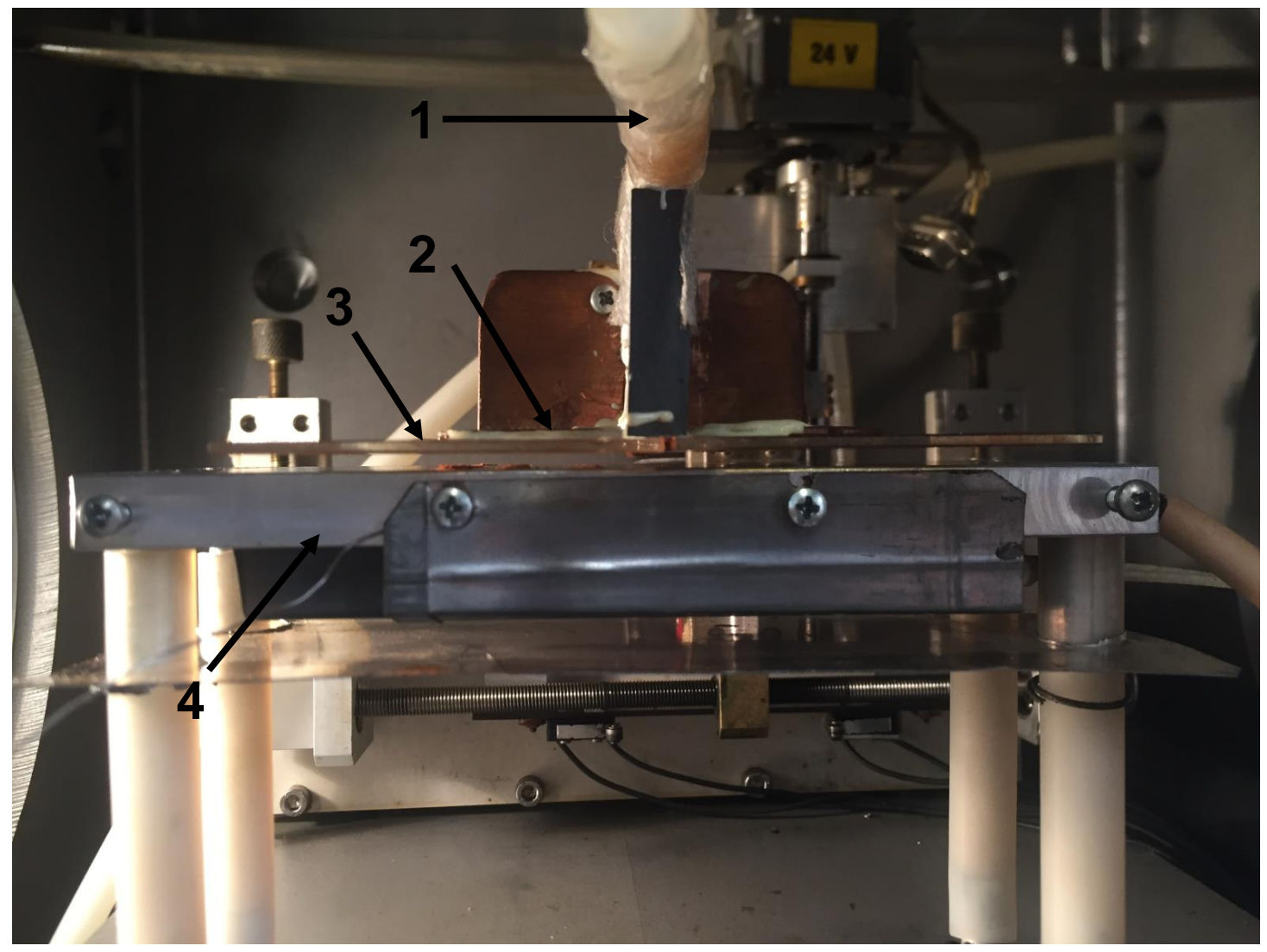

Figure 1. The image of electrode system. 1-gas inlet; 2-upper electrode; 3-glass; 4-lower heated electrode (without substrate).

The scheme of the electrode system can also be found in a previous study [25], where gas flow in the discharge gap was also modeled. The glass substrates were cleaned in a mixture of cyclohexane and isopropyl alcohol (1:1) and dried in airflow. Clean substrates were put into the reactor on the bottom electrode, which was then entirely covered by the substrate. The discharge gap between the substrate and the upper electrode was set to be $1.0 \mathrm{~mm}$. Before starting the depositions, the discharge chamber was pumped down to a pressure of $100 \mathrm{~Pa}$ and then filled with nitrogen to a pressure of $101 \mathrm{kPa}$. Atmospheric pressure during the deposition was maintained by slight pumping.

Nitrogen flow with flow rates from $50 \mathrm{sccm}$ to $400 \mathrm{sccm}$ bubbled through the liquid 2-methyl-2-oxazoline monomer in a glass bottle container. This flow was then mixed with the main nitrogen flow with the flow rate of $500 \mathrm{sccm}$. The temperature of the monomer was kept constant and set to $20^{\circ} \mathrm{C}$. The monomer flow rate was determined by weighing the monomer before and after the deposition, the flow rate of the monomer was $20 \mathrm{mg} \mathrm{s}^{-1}$ for the nitrogen flow of $100 \mathrm{sccm}$ through the liquid monomer. A high voltage with a frequency $6 \mathrm{kHz}$ was used for the generation of a dielectric barrier discharge in the discharge gap. The discharge was burning in homogeneous APTD mode [21], which is suitable for the deposition of homogeneous thin films. The discharge mode was checked by current-voltage measurements using an oscilloscope. The input power to a high voltage source was set to $55 \mathrm{~W}$ and kept constant in all experiments presented in this paper. The temperature of the bottom electrode was increased to a given value before the deposition. The upper electrode was periodically moving with a speed of $0.6 \mathrm{~cm} \mathrm{~s}^{-1}$ above the substrate during the deposition in order to ensure an even greater homogeneity of the deposited film. The deposition time was $23 \mathrm{~min}$. 


\subsection{Surface Characterization}

Deposited films were imaged with scanning electron microscope (SEM) MIRA3 (TESCAN, Brno, Czech Republic) with a Schottky field emission electron gun equipped with secondary electron and back-scattered electron detectors as well as a characteristic X-ray detector (EDX) analyzer (Oxford Instruments, High Wycombe, UK). The IR spectra of deposited films were measured by FTIR spectrometer Alpha (Bruker, Billerica, MA, USA) using a single reflection ATR module Platinum. The total surface free energy of the films was determined from measurements of contact angles between testing liquids and the film surfaces using a sessile-drop technique. Acid-base theory was used for the calculation of total surface free energy. Atomic Force Microscope (AFM) Ntegra Prima (NT-MDT, Apeldoorn, The Netherlands) was used to study the surface topography of the POx films. The measurements were performed in semicontact mode on $10 \times 10 \mu \mathrm{m}^{2}$ and $5 \times 5 \mu \mathrm{m}^{2}$ areas of each coating with a scanning rate of $0.5 \mathrm{~Hz}$. The 3D roughness parameters of the thin films were evaluated according to the ASME B46 standard using the NovaPx software (NT-MDT). The film thickness was measured using a Dektak XT (Bruker, Tucson, AZ, USA) mechanical profilometer.

\subsection{Characterization of Mechanical Properties}

Hardness $(H)$ and effective elastic modulus ( $\left.E_{\text {eff }}\right)$ of POx films were assessed by a nanoindentation tester Hysitron TI 950 TriboIndenter (Bruker, Minneapolis, MN, USA) with a load resolution of $1 \mathrm{nN}$. The effective elastic modulus could be expressed according to $E_{\text {eff }}=E /\left(1-v^{2}\right)$, where $v$ and $E$ are the Poisson's ratio and Young's modulus of the material, respectively. The standard Oliver and Pharr method [26] was used to calculate the above listed parameters. For a reliable characterization of mechanical properties of POx films several indentation modes were used including basic quasistatic indentation tests with trapezoid load function ( $5 \mathrm{~s}$ loading, $2 \mathrm{~s}$ creep, $5 \mathrm{~s}$ unloading), quasistatic nanoindentation tests with 33 partial unloading segments, and nanodynamic indentation (nanoDMA) in constant strain-rate measuring mode. The nanoDMA indentation tests were carried out by superimposing a sinusoidal load with a small amplitude $(30 \mu \mathrm{N}$ to $0.2 \mathrm{mN})$ and a frequency of $220 \mathrm{~Hz}$ on the quasistatic loading curve. From the sample response to this dynamic loading force, the dynamic displacement amplitude and the phase shift $\phi$ between this dynamic displacement and the input sinusiodal loading force were acquired. In order to decouple the indenter and the sample contribution from the the total spring stiffness, $k$, and the total damping coefficient, $C$, the Kelvin-Voigt mechanical equivalents model was used [27]. In this model, the indenter and the sample are described by a viscous damper and a purely elastic spring, which are connected in parallel. On the basis of the above described method, the storage modulus $E^{\prime}$, loss modulus $E^{\prime \prime}$, and loss factor $\tan \phi$ were calculated. Equation (1) shows the relationship between $E^{\prime}, E^{\prime \prime}$ and complex modulus (denoted as $E^{*}$ ):

$$
E^{\prime}=\frac{k_{s} \sqrt{\pi}}{2 \sqrt{A_{c}}} ; \quad E^{\prime \prime}=\frac{\omega C_{s} \sqrt{\pi}}{2 \sqrt{A_{c}}} ; \quad E^{*}=E^{\prime}+i E^{\prime \prime},
$$

where $i$ is the imaginary unit, $A_{c}$ is the projected contact area between the tip and the sample, $\omega$ is the angular frequency of the oscillating load, $k_{s}$ is the sample spring stiffness, and $C_{s}$ is the sample damping coefficient.

The maximum indentation load was varied between $100 \mu \mathrm{N}$ and $11 \mathrm{mN}$. The mechanical parameters were determined at indentation depths $<1 / 10$ of film thickness to avoid any substrate effect.

\subsection{Antibacterial Tests}

Bacterial culture Staphyloccocus epidermidis was grown into brain heart infusion (BHI) medium, and the temperature for microorganism cultivation was $37^{\circ} \mathrm{C}$. After $24 \mathrm{~h}$ incubation, S. epidermidis was diluted with new sterile medium to $1 \times 10^{8} \mathrm{CFU}$ per mL based on turbidity (NanoPhotometer ${ }^{\mathrm{TM}}$ P300, Implen, Munich, Germany). Then, S. epidermidis suspension ( $500 \mu \mathrm{L})$ was added on each sample. The bacteria on the surface of the samples were incubated for $24 \mathrm{~h}$ to allow the formation of biofilms. 
After incubation, all samples were washed twice with Milli-Q water to remove any loosely bound biofilm. For biofilms visualization, $200 \mu \mathrm{L}$ of Basic Red 2 stain was used. The excess of Basic Red 2 stain was then washed off and the results were evaluated using optical microscopy (Optical microscope Intraco Micro LM 666 PC / $\infty$ with Dino-Capture 2.0 software, Tachlovice, Czech Republic). Samples were imaged at least fifteen times each at random points, and the surface area covered by bacteria was quantified using images.

Other antibacterial tests were performed according to the ISO 22196 procedure with modifications. Before antibacterial testing, samples were sterilized by UV-radiation (wavelength of $258 \mathrm{~nm}$ ) for $30 \mathrm{~min}$. For the determination of antibacterial performance, gram-positive Staphylococcus aureus and gram-negative Escherichia coli were used. Bacterial suspensions (E. coli $3.4 \times 10^{6} \mathrm{CFU} \mathrm{mL}^{-1}$; S. aureus $8.9 \times 10^{5} \mathrm{CFU} \mathrm{mL}^{-1}$ ) were prepared in $1 / 500$ Nutrient broth (HiMedia laboratories, Mumbai, India). The bacterial suspension was dispensed on the sample surface (dimensions $25 \mathrm{~mm} \times 25 \mathrm{~mm}$ ) in the volume of $100 \mu \mathrm{L}$ and the sample was covered with the polypropylene foil (dimensions $20 \mathrm{~mm} \times$ $20 \mathrm{~mm}$ ). Samples with foils were cultivated at $35{ }^{\circ} \mathrm{C}$ and $100 \%$ relative humidity for $24 \mathrm{~h}$. After the incubation time, polypropylene foil was removed and each sample was completely washed by SCDLP (Soybean, Casein, Digest, Lecithin, Polysorbate) broth (HiMedia laboratories, India), which was subsequently collected. The viable bacteria count was determined by the pour plate culture method (PCA, HiMedia laboratories, India).

\subsection{Cytocompatibility Test}

The mouse embryonic fibroblast continuous cell line (NIH/3T3, ATCC ${ }^{\circledR}$ CRL-1658 ${ }^{\mathrm{TM}}$, Teddington, UK) was used for cytocompatibility test, according to the EN ISO 10993-5 standard, with modification. As a culture medium, the ATCC-formulated Dulbecco's Modified Eagle's Medium (BioSera, Nuaille, France), containing 10\% calf serum (BioSera, France) and Penicillin/Streptomycin at $100 \mathrm{U} \mathrm{mL}^{-1}$ (PAA Laboratories $\mathrm{GmbH}$, Pasching, Austria) was used. The tested samples were prepared with a dimension of $10 \mathrm{~mm} \times 10 \mathrm{~mm}$ and sterilized by UV-radiation (wavelength of $258 \mathrm{~nm}$ ) for $30 \mathrm{~min}$ and placed into the 24 well-plate. The cells were seeded onto the samples in the concentration of $1 \times 10^{4}$ for an hour for adhesion of the cells. After the precultivation, a sufficient amount of the medium was added and incubated for $72 \mathrm{~h}$ at $37^{\circ} \mathrm{C}$. The changes in cell morphology were observed with an inverted fluorescent microscope (Olympus, IX 81). In order to assess the cytotoxic effect, an MTT assay (Duchefa, Biochemie, Haarlem, The Netherlands) was performed. The absorbance was measured by an Infinite M200 Pro NanoQuant absorbance reader (Tecan, Männedorf, Switzerland). All tests were performed three times.

\section{Results}

The POx films were deposited at substrate temperatures $60{ }^{\circ} \mathrm{C}, 90^{\circ} \mathrm{C}, 120^{\circ} \mathrm{C}, 150{ }^{\circ} \mathrm{C}$, and at nitrogen flow of $100 \mathrm{sccm}$ through the monomer. It was found that the POx films deposited at substrate temperatures up to $90{ }^{\circ} \mathrm{C}$ can be washed by water from the substrate. Similar results were also observed in a study by other authors [18], where the POx films deposited at low RF power supplied to RF discharge were also soluble in water. So, films deposited at the substrate temperature of $150{ }^{\circ} \mathrm{C}$ will be characterized in the following subsections. The changes of nitrogen flow rate through the monomer influenced the film thickness only, so the depositions were performed with a nitrogen flow of $100 \mathrm{sccm}$.

\subsection{Surface Characterization}

The image from SEM of films deposited at $150{ }^{\circ} \mathrm{C}$ is shown in Figure 2. It can be seen from this image (and other images) that deposited films are smooth and without any pinholes. The elemental composition of POx films deposited at different substrate temperatures determined by EDX is shown in Table 1. 

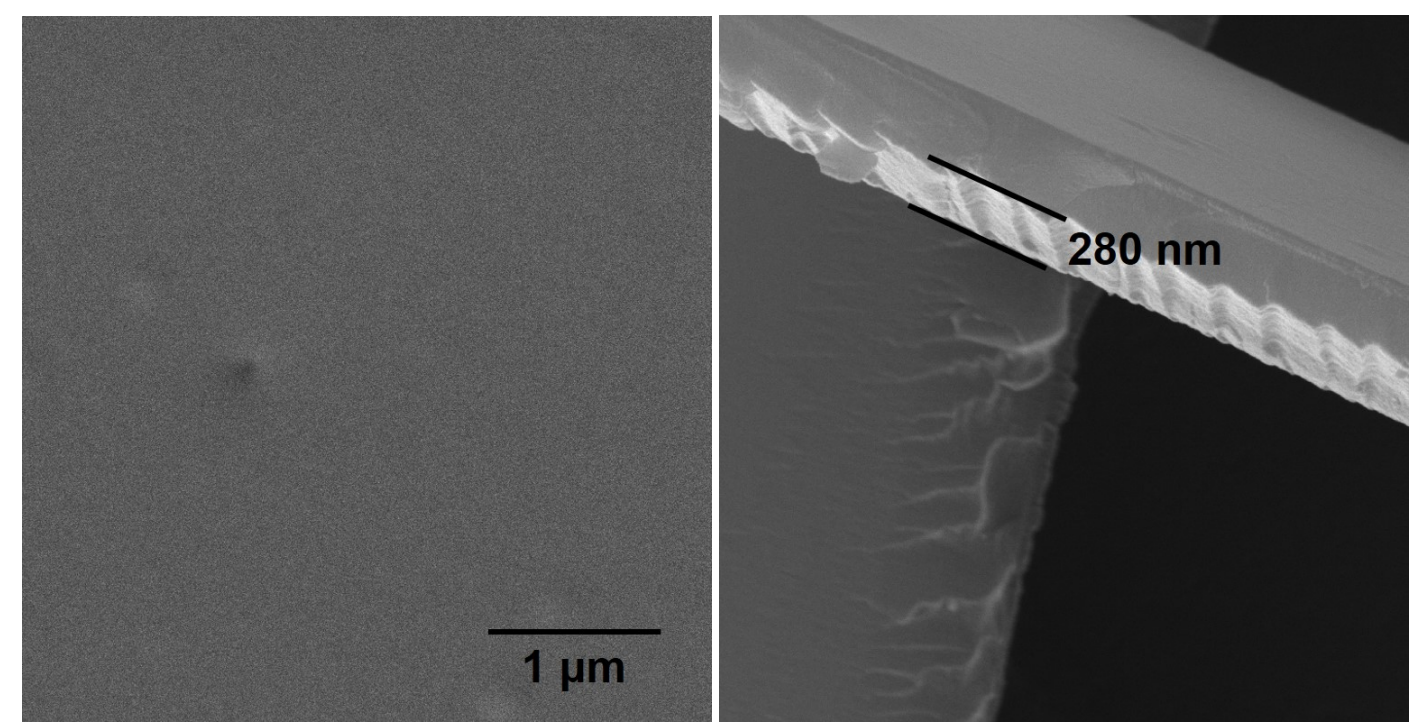

Figure 2. SEM images of polyoxazoline (POx) film deposited at $150{ }^{\circ} \mathrm{C}$. Left images-surface of deposited film, magnification $10 \mathrm{k} \times$; right image—deposited film removed from the substrate by scratch, magnification $50 \mathrm{k} \times$.

Table 1. The elemental composition of films deposited at different substrate temperatures. The elemental composition is given in atomic \%.

\begin{tabular}{ccccc}
\hline Element & $\mathbf{6 0}{ }^{\circ} \mathbf{C}$ & $\mathbf{9 0}{ }^{\circ} \mathbf{C}$ & $\mathbf{1 2 0}^{\circ} \mathbf{C}$ & $\mathbf{1 5 0}{ }^{\circ} \mathbf{C}$ \\
\hline $\mathrm{C}$ & 43 & 43 & 47 & 48 \\
$\mathrm{~N}$ & 40 & 41 & 42 & 39 \\
$\mathrm{O}$ & 17 & 16 & 11 & 13 \\
\hline
\end{tabular}

The nitrogen content in the films was increased by up to $40 \%$ in comparison with nitrogen content in 2-methyl-2-oxazoline. The oxygen content corresponds to oxygen content in 2-methyl-2-oxazoline at substrate temperatures of $60^{\circ} \mathrm{C}$ and $90^{\circ} \mathrm{C}$ and it decreases to lower values at substrate temperatures of $120^{\circ} \mathrm{C}$ and $150{ }^{\circ} \mathrm{C}$. Additionally, carbon content increases at higher substrate temperatures.

The contact angles between the test liquids and POx films were measured in order to determine the total surface free energy using the sessile drop technique. Three test liquids were used-distilled water, glycerol, and diiodomethane $\left(\mathrm{CH}_{2} \mathrm{I}_{2}\right)$. The acid-base theory with multiple regression [28] was used to calculate the total surface free energy and its components-the Lifshitz-van der Walls (LW) interaction component and the acid-base $(\mathrm{AB})$ interaction component. The surface free energy and its abovementioned components of POx films are given in Table 2.

Table 2. The contact angles for different liquids and surface free energy and its components of POx films deposited at different substrate temperatures.

\begin{tabular}{ccccccc}
\hline Sample & \multicolumn{3}{c}{ Contact Angle $\left(^{\circ}\right)$} & \multicolumn{2}{c}{ Surface Free Energy $\left(\mathbf{m J} / \mathbf{m}^{\mathbf{2}}\right)$} \\
\hline & $\mathbf{C H}_{\mathbf{2}} \mathbf{I}_{\mathbf{2}}$ & Glycerol & Water & Total & LW & AB \\
\hline substrate & $59.8 \pm 1.2$ & $35.5 \pm 2.0$ & $33.4 \pm 2.3$ & $52.6 \pm 1.0$ & $28.7 \pm 0.7$ & $23.9 \pm 2.0$ \\
$60{ }^{\circ} \mathrm{C}$ & $40.5 \pm 1.0$ & $28.9 \pm 0.8$ & $10.0 \pm 2.0$ & $56.6 \pm 0.7$ & $39.4 \pm 0.6$ & $17.3 \pm 1.2$ \\
$90{ }^{\circ} \mathrm{C}$ & $40.8 \pm 1.4$ & $38.3 \pm 0.5$ & $16.1 \pm 0.9$ & $50.3 \pm 0.9$ & $39.2 \pm 0.6$ & $11.2 \pm 1.4$ \\
$120{ }^{\circ} \mathrm{C}$ & $60.8 \pm 1.7$ & $50.5 \pm 1.8$ & $40.0 \pm 2.8$ & $42.4 \pm 1.9$ & $28.1 \pm 1.9$ & $14.3 \pm 2.8$ \\
$150{ }^{\circ} \mathrm{C}$ & $60.6 \pm 4.0$ & $46.6 \pm 1.7$ & $21.9 \pm 2.7$ & $43.3 \pm 1.8$ & $27.8 \pm 2.8$ & $15.5 \pm 4.0$ \\
\hline
\end{tabular}

All POx films were hydrophilic, their surface energy is in the range from 42.4 to $56.6 \mathrm{~mJ} \mathrm{~m}^{-2}$. The thickness, hardness, and effective elastic modulus of POx films are given in Table 3. 
Table 3. The film thickness, hardness, and effective elastic modulus of POx films deposited at different substrate temperatures.

\begin{tabular}{cccc}
\hline Sample & Thickness $(\boldsymbol{\mu m})$ & Hardness $(\mathrm{GPa})$ & $\boldsymbol{E}_{\text {eff }}(\mathrm{GPa})$ \\
\hline $60^{\circ} \mathrm{C}$ & $1.5 \pm 0.2$ & $0.70 \pm 0.10$ & $15 \pm 1$ \\
$90^{\circ} \mathrm{C}$ & $1.7 \pm 0.1$ & $0.55 \pm 0.05$ & $11 \pm 1$ \\
$120^{\circ} \mathrm{C}$ & $1.1 \pm 0.1$ & $0.55 \pm 0.05$ & $11 \pm 1$ \\
$150^{\circ} \mathrm{C}$ & $0.6 \pm 0.1$ & $0.60 \pm 0.05$ & $15 \pm 1$ \\
\hline
\end{tabular}

The film thickness decreases with increasing substrate temperature at the deposition. This dependence is in agreement with the findings in previous experiments [22,23]. From the point of view of mechanical properties, the films showed polymer-like viscoelastic character. However, compared to common polymer materials (e.g., polycarbonate, polyethylene, polypropylene), they exhibited significantly higher hardness and effective elastic modulus (for example the hardness of polycarbonate is $0.18 \mathrm{GPa}$ and its elastic modulus is around $3 \mathrm{GPa}$ ). The time dependent mechanical response of polymer materials may be characterized using the storage modulus $E^{\prime}$, loss modulus $E^{\prime \prime}$, and loss factor $\tan \phi$. The storage modulus $E^{\prime}$ is the measure of the energy stored and recovered during the loading period, and the loss modulus $E^{\prime \prime}$ is the measure of the energy dissipated in the studied material during the loading period. The loss factor $\tan \phi$ is the measure of viscoelastic behavior of materials [27]. The studied POx films exhibited relatively low $\tan \phi$ values indicating a predominantly elastic behavior (low damping) of the film material, see Table 4 .

The AFM images of POx films are shown in Figure 3.
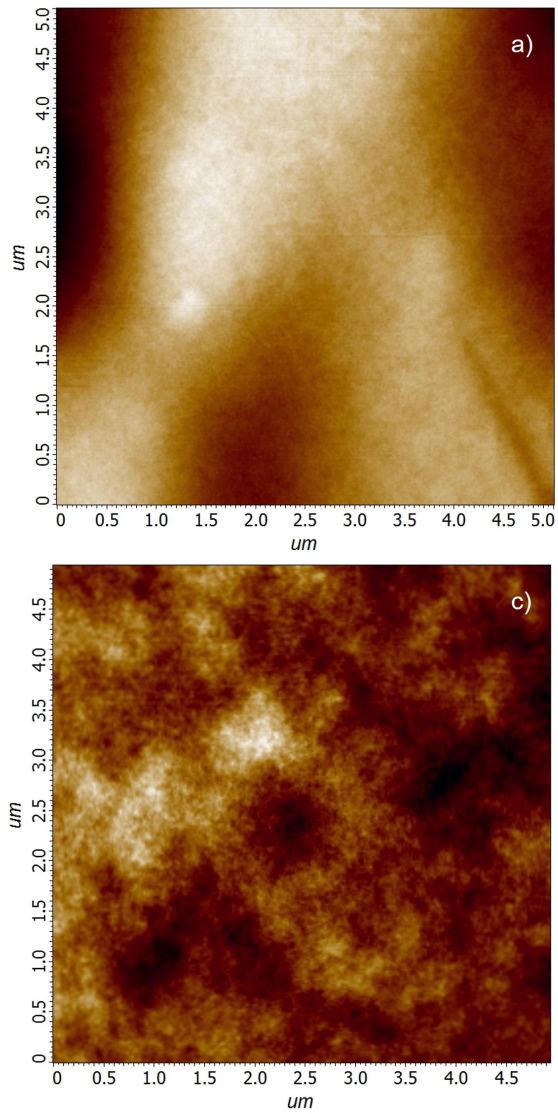
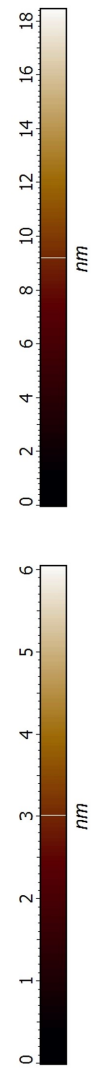
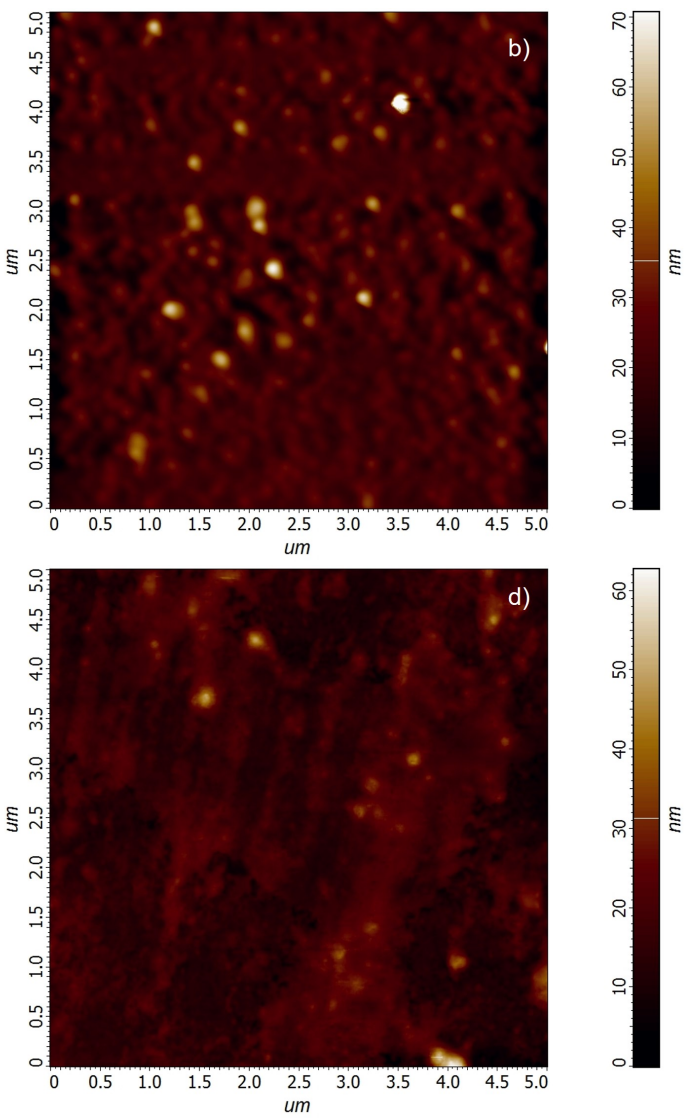

Figure 3. Atomic Force Microscope (AFM) images of POx films deposited at different substrate temperatures. (a) $60{ }^{\circ} \mathrm{C}$; (b) $90^{\circ} \mathrm{C}$; (c) $120^{\circ} \mathrm{C}$; (d) $150{ }^{\circ} \mathrm{C}$. 
Table 4. The results of the nanodynamic indentation (nanoDMA) measurements: storage modulus $E^{\prime}$, loss modulus $E^{\prime \prime}$, and loss factor $\tan \phi$ of POx films deposited at different substrate temperatures.

\begin{tabular}{cccc}
\hline Sample & $\boldsymbol{E}^{\prime}(\mathrm{GPa})$ & $\boldsymbol{E}^{\prime \prime}(\mathrm{GPa})$ & $\tan \boldsymbol{\phi}$ \\
\hline $60^{\circ} \mathrm{C}$ & $16 \pm 2$ & $0.50 \pm 0.05$ & $0.031 \pm 0.005$ \\
$90^{\circ} \mathrm{C}$ & $11 \pm 1$ & $0.30 \pm 0.04$ & $0.027 \pm 0.006$ \\
$120^{\circ} \mathrm{C}$ & $12 \pm 1$ & $0.37 \pm 0.05$ & $0.031 \pm 0.005$ \\
$150^{\circ} \mathrm{C}$ & $14 \pm 1$ & $0.48 \pm 0.05$ & $0.034 \pm 0.005$ \\
\hline
\end{tabular}

The film roughness values determined from AFM measurements are given in Table 5. Instead of the commonly used root mean square (RMS) roughness and average roughness values, the area peak-to-valley height $S_{\mathrm{t}}$ and area peak density $S d_{\mathrm{s}}$ values [29] were added in order to illustrate the change of the film surface structure with the preparation temperature.

Table 5. The film roughness of POx films deposited at different substrate temperatures. $S_{\mathrm{q}}$-root mean square (RMS) roughness; $S_{\mathrm{a}}$-average roughness; $S_{\mathrm{t}}$-RMS roughness, area peak-to-valley height; $S d_{\mathrm{s}}$-area peak density.

\begin{tabular}{ccccc}
\hline Sample & $S_{\mathbf{q}}(\mathbf{n m})$ & $S_{\mathbf{a}}(\mathbf{n m})$ & $S_{\mathbf{t}}(\mathbf{n m})$ & $S d_{\mathbf{s}}\left(\mu \mathbf{m}^{-2}\right)$ \\
\hline $60^{\circ} \mathrm{C}$ & 3.3 & 2.7 & 86.0 & 170 \\
$90^{\circ} \mathrm{C}$ & 6.2 & 4.2 & 70.6 & 140 \\
$120^{\circ} \mathrm{C}$ & 7.3 & 6.8 & 48.9 & 88 \\
$150^{\circ} \mathrm{C}$ & 4.8 & 3.7 & 62.6 & 278 \\
\hline
\end{tabular}

\subsection{FTIR Analysis}

The FTIR spectra of deposited POx thin films are shown in Figure 4.

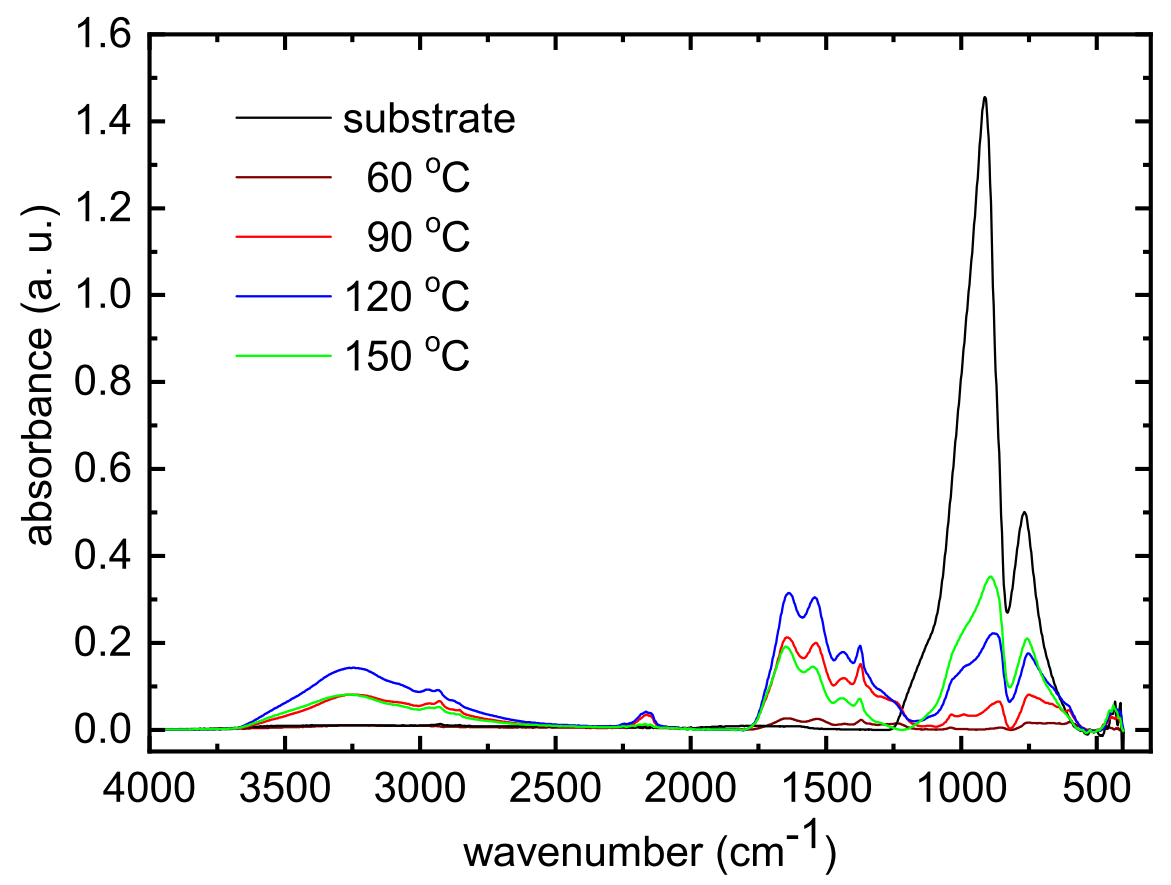

Figure 4. FTIR spectra of thin films deposited at different substrate temperatures.

Very low absorbance for the film deposited at substrate temperature of $60{ }^{\circ} \mathrm{C}$ was caused by small film thickness. Broad absorption band in the range $3000-3600 \mathrm{~cm}^{-1}$ consists of several peaks belonging to $\mathrm{OH}, \mathrm{NH}$, and $\mathrm{NH}_{2}$ groups. The bands at $2950 \mathrm{~cm}^{-1}, 1450 \mathrm{~cm}^{-1}$, and $1370 \mathrm{~cm}^{-1}$ are characteristic for vibrations of $\mathrm{CH}_{3}$ and $\mathrm{CH}_{2}$ groups. The band at $2170 \mathrm{~cm}^{-1}$ can be attributed to alkyne 
$\mathrm{C} \equiv \mathrm{C}$ and / or isocyanate $\mathrm{O}=\mathrm{C}=\mathrm{N}$ and nitrile $\mathrm{C} \equiv \mathrm{N}$. Such chemical bonds are not present at traditional polymerization of oxazolines and they can be attributed to fragmentation and recombination of the oxazoline monomer during plasma polymerization. The band between $1790 \mathrm{~cm}^{-1}$ and $1590 \mathrm{~cm}^{-1}$ is characteristic for stretching vibration $\mathrm{C}=\mathrm{N}$ bond constituting the oxazoline ring. Its presence in the $\mathrm{IR}$ spectrum indicates the presence of oxazoline rings in deposited films. The band around $1550 \mathrm{~cm}^{-1}$ belongs to N-H bonds. Finally, the bands below $1000 \mathrm{~cm}^{-1}$ belong to Si-O-Si or Si-O bonds from substrate glass.

\subsection{Antibacterial Properties}

Firstly, the antibacterial test was done using S. epidermidis, which was also used in previous studies $[16,18]$. Experiments were repeated twice using two identical series. It can be concluded that the results showed significant differences between the uncoated sample and samples with deposited films, see Figure 5. Bacteria on POx films were not able to form a biofilm. It can be observed in the microscopy image where only individual or small colonies are observed. In comparison, the bacteria growing on the untreated surface formed a biofilm. The possible explanations of antibiofouling properties can be found in a recent review [30].
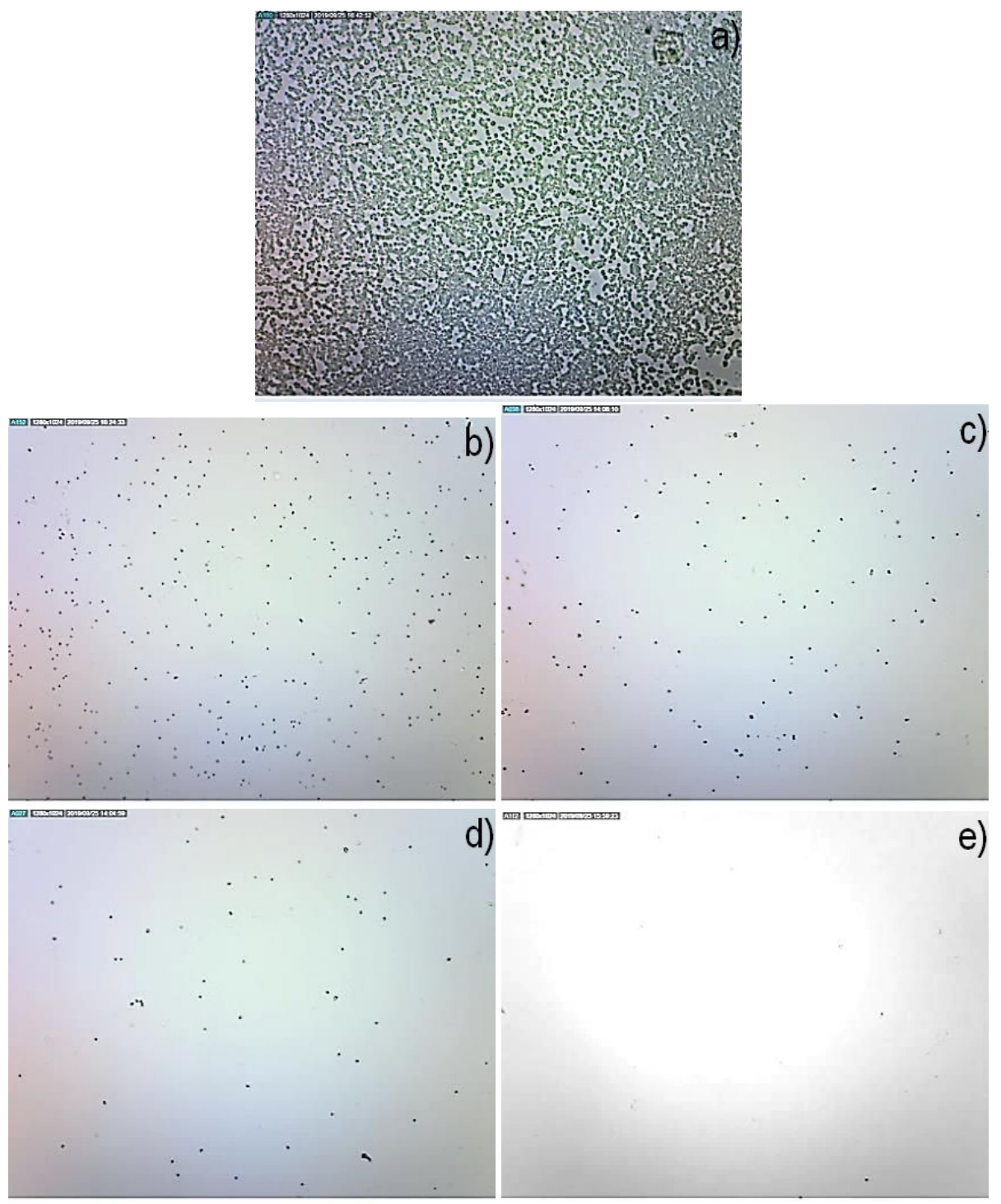

Figure 5. Images of films deposited at different substrate temperatures with bacteria S. epidermidis. (a) blank substrate; (b) $60^{\circ} \mathrm{C}$; (c) $90^{\circ} \mathrm{C}$; (d) $120^{\circ} \mathrm{C}$; (e) $150{ }^{\circ} \mathrm{C}$. 
Before adding the micro-organism and incubation, some samples were washed once or twice with sterile Milli-Q water in order to test the stability of prepared POx films. The results are shown in Figure 6.

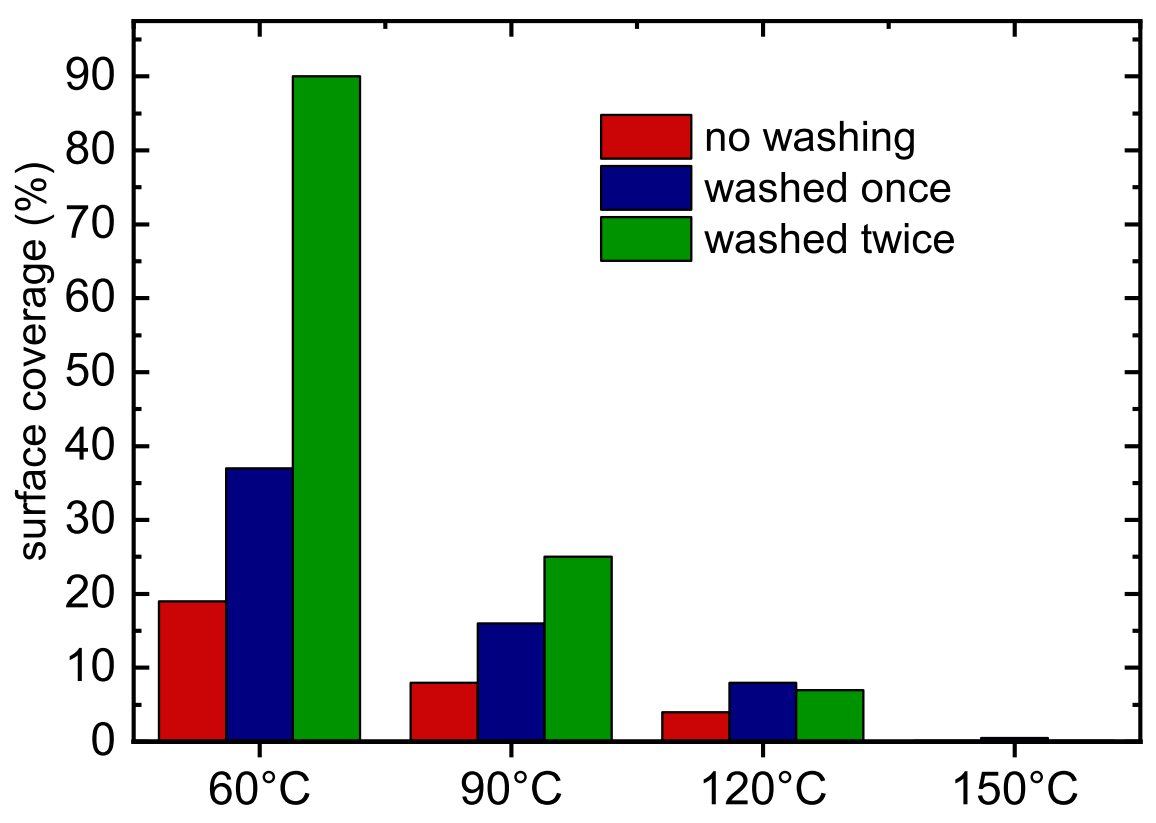

Figure 6. Bacteria S. epidermidis surface coverage area (percent) formed on POx films deposted at different substrate temperatures.

The films deposited at substrate temperatures of $60^{\circ} \mathrm{C}$ and $90{ }^{\circ} \mathrm{C}$ are soluble in water and their antibiofouling properties decrease after their washing by water. On the other hand, the films deposited at substrate temperatures of $120^{\circ} \mathrm{C}$ and $150{ }^{\circ} \mathrm{C}$ are not soluble in water and the washing does not decrease their antibiofouling properties significantly.

Secondly, the other antibacterial tests were done using S. aureus and E. coli according to the ISO 22196 procedure. Antibacterial activity against S. aureus and E. coli strains after $72 \mathrm{~h}$ of incubation time for the samples is listed in Table 6.

Table 6. Antibacterial activity results of studied POx films.

\begin{tabular}{ccc}
\hline Sample & S. aureus $\left(\mathrm{CFU} / \mathrm{cm}^{2}\right)$ & E. coli $\left(\mathrm{CFU} / \mathrm{cm}^{2}\right)$ \\
\hline substrate & $1.3 \times 10^{6}$ & $2.0 \times 10^{5}$ \\
$60^{\circ} \mathrm{C}$ & $<1$ & 4.4 \\
$90^{\circ} \mathrm{C}$ & $<1$ & 1.1 \\
$120^{\circ} \mathrm{C}$ & $<1$ & 4.4 \\
$150^{\circ} \mathrm{C}$ & 1.6 & 5.4 \\
\hline
\end{tabular}

The reference substrate glass was open to both gram-positive and -negative bacterial contamination and did not perform any antibacterial effect, as expected. Nevertheless, counted viable gram-positive $S$. aureus level was found almost five times higher than the gram-negative E. coli strain. The oxazoline-based thin film deposited samples were highly active against both S. aureus and E. coli strains. The effect of the oxazoline-based thin film against $S$. aureus was slightly higher compared to E. coli, but the differences were negligible. Among them, as it can be seen in Table 6, the sample deposited at $150^{\circ} \mathrm{C}$ performed slightly lower antibacterial activity against both strains compared to other oxazoline-based thin film deposited samples, probably due to its higher bonding performance. However, it is also negligible, since the difference is extremely low. The antibacterial activity against 
S. aureus and E. coli depends on the cell-wall compositions of the bacterial strains and physicochemical characteristics with an efficiency and the releasing performance of the deposited oxazoline-based thin films. Therefore, the level of successfully deposited oxazoline-based thin films onto the glass substrate plays a critical role. Moreover, it strictly depends on the surface characteristics, such as wettability, roughness, charge density, and functionality.

\subsection{Cytocompatibility Results}

An in vitro cytocompatibility test was performed by mouse embryonic fibroblast cells (NIH/3T3) on the samples for $72 \mathrm{~h}$ and results are shown in Figure 7.

As can be seen from Figure 7, all types of modifications promote cell viability compared to blank glass substrate which was taken as reference. Films deposited at $60{ }^{\circ} \mathrm{C}$ and $90{ }^{\circ} \mathrm{C}$ exhibit almost identical cell viability as the reference. However, in the case of the film deposited at $120^{\circ} \mathrm{C}$, the viability increased significantly when reaching the value of almost $180 \%$. The highest fibroblasts cell viability was observed for the film deposited at $150{ }^{\circ} \mathrm{C}$ when the value was more than $270 \%$ which signifies an excellent compatibility to the used cell substrate. The abovementioned results suggest that oxazoline-based thin films are affecting cell behavior, especially cell attachment. Moreover, with rising deposition temperature, the cell viability value is increasing.

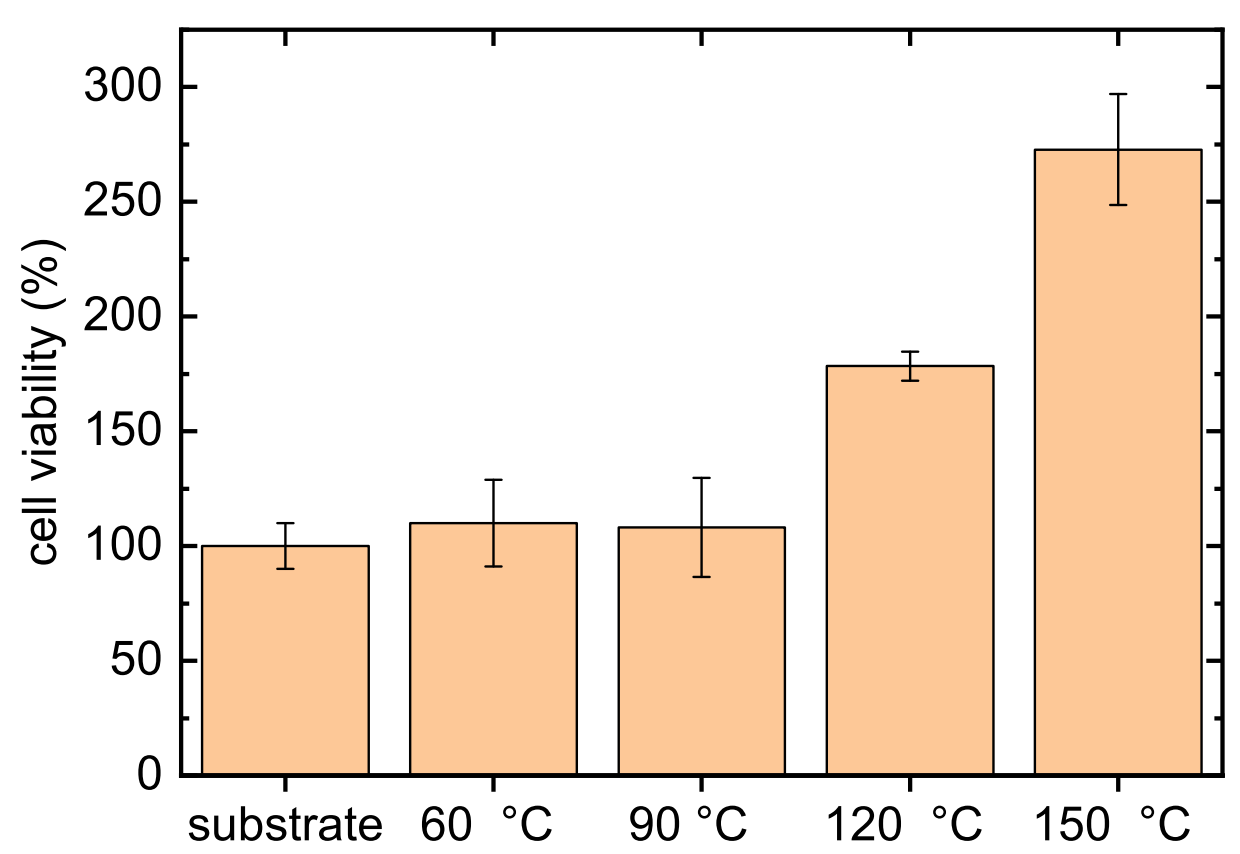

Figure 7. In vitro cytocompatibility results of tested POx films deposited at different substrate temperatures.

\section{Discussion}

The oxazoline-based thin films were successfully deposited on glass substrates in atmospheric pressure dielectric barrier discharge. Nitrogen was used as the working gas for the discharge, 2-methyl-2-oxazoline vapors were admixed to the nitrogen flow and used as the monomer. This gas composition made it possible to obtain a homogeneous discharge, which led to the deposition of homogeneous thin films. To improve the film properties, it was necessary to increase the substrate temperature during the deposition. The deposited films were smooth and without any pinholes. The films deposited at substrate temperatures of $60{ }^{\circ} \mathrm{C}$ and $90{ }^{\circ} \mathrm{C}$ were soluble in water and they also did not exhibit increased cell viability compared to the blank glass substrate. It was found from FTIR spectra that some oxazoline rings are still present in the plasma polymer in contrast to classical oxazoline polymerization. The retention of the oxazoline ring is assumed to be highly beneficial for 
selected biomedical applications. On the other hand, some fragmentation and recombination of the oxazoline monomer was also observed in FTIR spectra. These findings are in agreement with the results of oxazoline plasma polymerization in low-pressure RF discharge [16]. However, higher N:C elemental ratio (0.93-0.81) was observed in films deposited in nitrogen APTD in this study, whereas lower N:C ratio (0.31-0.24) was observed at films deposited in RF discharge [16]. Nitrogen-rich surfaces are known for their excellent biocompatibility [31]. The best cell viability results were found at films deposited at substrate temperatures of $120^{\circ} \mathrm{C}$ and $150{ }^{\circ} \mathrm{C}$. Lower cell viability on films deposited at substrate temperatures of $60^{\circ} \mathrm{C}$ and $90^{\circ} \mathrm{C}$ can be explained by their dissolvability in aqueous solvents. All deposited films exhibited excellent antibacterial properties against all bacterial strains used for antibacterial tests. Deposited films could be used as coatings with antibacterial and antibiofouling properties for biomedical applications.

Author Contributions: Conceptualization, D.T. and M.L.; methodology, P.M. and P.H.; validation, P.S. and M.L.; formal analysis, D.T. and L.P.; investigation, P.S., K.T., P.M., A.B., J.J., L.P., V.B., R.P., P.H., and K.O.; resources, P.M.; writing-original draft preparation, D.T., M.L., and P.M.; writing-review and editing, D.T. and M.L.; visualization, V.M.; supervision, D.T.

Funding: This research was funded by the Ministry of Education, Youth and Sports of the Czech Republic, project LO1411 (NPU I), and by Czech Science Foundation under project GACR 19-15240S. V.M. was supported by institutional support for the research organization development awarded by the Ministry of Defence of the Czech Republic.

Conflicts of Interest: The authors declare no conflict of interest.

\section{References}

1. Woodle, M.C.; Engbers, C.M.; Zalipsky, S. New Amphipatic Polymer Lipid Conjugates Forming Long-Circulating Reticuloendothelial System-Evading Liposomes. Bioconj. Chem. 1994, 5, $493-496$. [CrossRef] [PubMed]

2. Zalipsky, S.; Hansen, C.B.; Oaks, J.M.; Allen, T.M. Evaluation of Blood Clearance Rates and Biodistribution of Poly(2-oxazoline)-grafted Liposomes. J. Pharm. Sci. 1996, 85, 133-137. [CrossRef] [PubMed]

3. Goddard, P.; Hutchinson, L.E.; Brown, J.; Brookman, L.J. Soluble Polymeric Carriers for Drug Delivery. Part 2. Preparation and in Vivo Behaviour of N-acylethylenimine Copolymers. J. Control. Release 1989, 10, 5-16. [CrossRef]

4. Jordan, R.; Ulman, A. Surface Initiated Living Cationic Polymerization of 2-Oxazolines. J. Am. Chem. Soc. 1998, 120, 243-247. [CrossRef]

5. Bouten, P.J.M.; Hertsen, D.; Vergaelen, M.; Monnery, B.D.; Boerman, M.A.; Goossens, H.; Catak, S.; van Hest, J.C.M.; Van Speybroeck, V.; Hoogenboom, R. Accelerated Living Cationic Ringopening Polymerization of a Methyl Ester Functionalized 2-Oxazoline Monomer. Polym. Chem. 2015, 6, 514-518. [CrossRef]

6. Wang, H.; Li, L.; Tong, Q.; Yan, M. Evaluation of Photochemically Immobilized Poly(2-ethyl-2-oxazoline) Thin Films as Protein-Resistant Surfaces. ACS Appl. Mater. Interfaces 2011, 3, 3463-3471. [CrossRef]

7. Pidhatika, B.; Rodenstein, M.; Chen, Y.; Rakhmatullina, E.; Mühlebach, A.; Acikgöz, C.; Textor, M.; Konradi, R. Comparative Stability Studies of Poly(2-methyl-2-oxazoline) and Poly(ethyleneglycol) Brush Coatings. Biointerphases 2012, 7. [CrossRef]

8. Vasilev, K. Nanoengineered Plasma Polymer Films for Biomaterial Applications. Plasma Chem. Plasma Process. 2014, 34, 545-558. [CrossRef]

9. Siow, K.S.; Britcher, L.; Kumar S.; Griesser, H.J. Plasma Methods for the Generation of Chemically Reactive Surfaces for Biomolecule Immobilization and Cell Colonization-A Review. Plasma Processes Polym. 2006, 3, 392-418. [CrossRef]

10. Lieberman, M.A.; Lichtenberg, A.J. Principles of Plasma Discharges and Materials Processing, 2nd ed.; John Wiley \& Sons: Hoboken, NJ, USA, 2005.

11. Duan, S.; Liu, X.; Wang, Y.; Meng, Y.; Alsaedi, A.; Hayat, T.; Li, J. Plasma Surface Modification of Materials and Their Entrapment of Water Contaminant: A Review. Plasma Process Polym. 2017, 14, e1600218. [CrossRef] 
12. Yue, M.; Zhou, B.; Jiao, K.; Qian, X.; Xu, Z.; Teng, K.; Zhao, L.; Wang, J.; Jiao, Y. Switchable Hydrophobic/Hydrophilic Surface of Electrospun Poly(l-lactide) Membranes Obtained by CF4 Microwave Plasma Treatment. Appl. Surf. Sci. 2015, 327, 93-99. [CrossRef]

13. Wu, H.; Zhou, Z.; Chen, L.; Li, W.; Han, Q.; Li, C.; Xu, Z.; Qian, X. PECVD-Induced Growing of Diverse Nanomaterials on Carbon Nanofibers under Various Conditions. Mater. Lett. 2018, 216, 291-294. [CrossRef]

14. Zhang, C.; Liu, L.; Xu, Z.; Lv, H.; Wu, N.; Zhou, B.; Mai, W.; Zhao, L.; Tian, X.; Guo, X. Improvement for Interface Adhesion of Epoxy/Carbon Fibers Endowed With Carbon Nanotubes via Microwave Plasma-Enhanced Chemical Vapor Deposition. Polym. Compos. 2018, 39, E1262-E1268. [CrossRef]

15. Elias, M.; Kloc, P.; Jasek, O.; Mazankova, V.; Trunec, D.; Hrdy, R.; Zajickova, L.; Atmospheric Pressure Barrier Discharge at High Temperature: Diagnostics and Carbon Nanotubes Deposition. J. Appl. Phys. 2015, 117, 103301. [CrossRef]

16. Ramiasa, M.; Cavallaro, A.; Mierczynska, A.; Christo, S.; Gleadle, J.; Hayball, J.D.; Vasilev, K. Plasma Polymerised PolyOxazoline Thin Films for Biomedical Applications. Chem. Commun. 2015, 51, 4279-4282. [CrossRef] [PubMed]

17. Macgregor-Ramiasa, M.N.; Cavallaro, A.A.; Vasilev, K. Properties and Reactivity of Polyoxazoline Plasma Polymer Films. J. Mater. Chem. B 2015, 3, 6327-6337. [CrossRef]

18. Cavallaro, A.A.; Macgregor-Ramiasa, M.N.; Vasilev, K. Antibiofouling Properties of Plasma-Deposited Oxazoline-Based Thin Films. ACS Appl. Mater. Interfaces 2016, 8, 6354-6362. [CrossRef]

19. Gherardi, N.; Gouda, G.; Gat, E.; Ricard, A.; Massines, F. Transition from Glow Silent Discharge to Micro-discharges in Nitrogen Gas. Plasma Sources Sci. Technol. 2000, 9, 340-346. [CrossRef]

20. Gherardi, N.; Martin, S.; Massines, F. A New Approach to $\mathrm{SiO}_{2}$ Deposit using a $\mathrm{N}_{2}-\mathrm{SiH}_{4}-\mathrm{N}_{2} \mathrm{O}$ Glow Dielectric Barrier-Controlled Discharge at Atmospheric Pressure. J. Phys. D: Appl. Phys. 2000, 33, L104-L108. [CrossRef]

21. Trunec, D.; Navratil, Z.; Stahel, P.; Zajickova, L.; Bursikova, V.; Cech, J. Deposition of Thin Organosilicon Polymer Films in Atmospheric Pressure Glow Discharge. J. Phys. D Appl. Phys. 2004, 37, 2112-2120. [CrossRef]

22. Trunec, D.; Zajickova, L.; Bursikova, V.; Studnicka, F.; Stahel, P.; Prysiazhnyi, V.; Perina, V.; Houdkova, J.; Navratil, Z.; Franta, D. Deposition of Hard Thin Films from HMDSO in Atmospheric Pressure Dielectric Barrier Discharge. J. Phys. D Appl. Phys. 2010, 43, 225403. [CrossRef]

23. Al-Bataineh, S.A.; Cavallaro, A.A.; Michelmore, A.; Macgregor, M.N.; Whittle, J.D.; Vasilev, K., Deposition of 2-oxazoline- based Plasma Polymer Coatings using Atmospheric Pressure Helium Plasma Jet. Plasma Process Polym. 2019, 16, e1900104. [CrossRef]

24. Van Guyse, J.F.R.; Cools, P.; Egghe, T.; Asadian, M.; Vergaelen, M.; Rigole, P.; Yan, W.; Benetti, E.M.; Jerca, V.; Declercq, H.; et al. Influence of the Aliphatic Side Chain on the Near Atmospheric Pressure Plasma Polymerization of 2-Alkyl-2-oxazolines for Biomedical Applications. ACS Appl. Mater. Interfaces 2019, 11, 31356-31366. [CrossRef] [PubMed]

25. Obrusnik, A.; Jelinek, P.; Zajickova, L. Modelling of the Gas Flow and Plasma Co-polymerization of Two Monomers in an Atmospheric-Pressure Dielectric Barrier Discharge. Surf. Coat. Technol. 2017, 314, $139-147$. [CrossRef]

26. Oliver, W.C.; Pharr, G.M. An Improved Technique for Determining Hardness and Elastic Modulus using Load and Displacement Sensing Indentation Experiments. J. Mater. Res. 1992, 7, 1564-1583. [CrossRef]

27. Zlotnikov, I.; Zolotoyabko, E.; Fratzl, P. Nano-scale Modulus Mapping of Biological Composite Materials: Theory and Practice Prog. Mater. Sci. 2017, 87, 292-320. [CrossRef]

28. Navratil, Z.; Bursikova, V.; Stahel, P.; Sira, M.; Zverina, P. On the Analysis of Surface Free Energy of DLC Coatings Deposited in Low Pressure RF Discharge. Czech. J. Phys. (Suppl. C) 2004, 54, C877-C882. [CrossRef]

29. Deltombe R.; Kubiak K.J.; Bigerelle M. How to Select the Most Relevant 3D Roughness Parameters of a Surface. Scanning 2014, 36, 150-160. [CrossRef] 
30. Katsikogianni, M.; Missirlis, Y.F. Concise Review of Mechanisms of Bacterial Adhesion to Biomaterials and of Techniques Used in Estimating Bacteria-Material Interactions. Eur. Cells Mater. 2004, 8, 37-57. [CrossRef]

31. Lerouge, S.; Major, A.; Girault-Lauriault, P.-L.; Raymond, M.-A.; Laplante, P.; Soulez, G.; Mwale, F.; Wertheimer, M.R.; Hébert, M.-J. Nitrogen-Rich Coatings for Promoting Healing around Stent-Grafts after Endovascular Aneurysm Repair. Biomaterials 2007, 28, 1209-1217. [CrossRef]

(C) 2019 by the authors. Licensee MDPI, Basel, Switzerland. This article is an open access article distributed under the terms and conditions of the Creative Commons Attribution (CC BY) license (http:/ / creativecommons.org/licenses/by/4.0/). 